\title{
"Find Your Personal Elements": An Engaging Approach to Introducing Chemistry to Secondary School Students
}

\author{
Teresa Rodríguez-Blas,* Andrés de Blas, María-Jesús Latorre-López, and Sofía Picos-Nebril*
}

Cite This: J. Chem. Educ. 2021, 98, 2012-2016

Read Online

ABSTRACT: Creative educational methodologies capable of engaging students in interactive, enjoyable learning help to lessen students' anxieties and motivate them. In this context and with the objective of making easier the learning of the chemical symbols and periodic table as well as introducing the concept of chemical formula, we have designed the activity called FYPE (Find Your Personal Elements). Conceived not as a game but as a fun and entertaining activity to introduce chemistry to secondary students, FYPE has been found to be very motivating. It is aimed at eighth-grade students (13-14 years old), corresponding to the second course of Compulsory Secondary Education in Spain, when the first contact of our students with chemistry as an independent subject occurs. FYPE is composed of three complementary and consecutive parts: (i) writing your "chemical name", (ii) a flash presentation, and (iii) an art exhibition. It takes place over a month and a half, ending with an open activity in

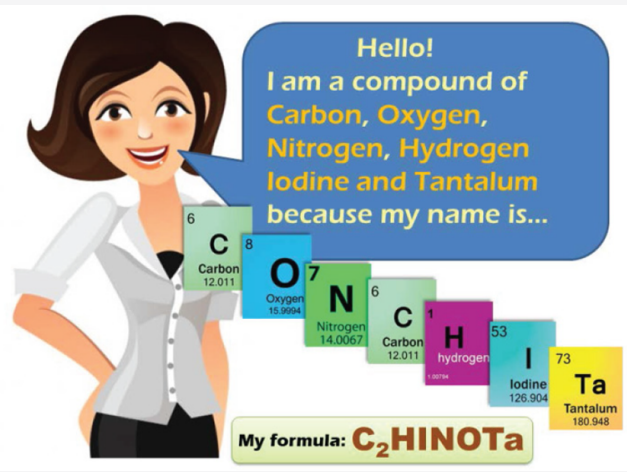
the main hall of the high school in which parents and relatives also participate, making this activity go beyond the classroom. In a pleasant way, the concept of chemical formula is easily understood by the students, who also discover for themselves many elements that they had never heard of. The students' perception of the activity was assessed by means of a survey and found to be very positive, with a score of 8.20 (maximum 10). The result showed that $77 \%$ of the students considered FYPE to be "great fun", and $82 \%$ of them admitted that FYPE "had helped them to get to learn about elements that they did not know existed". Around $60 \%$ found that "chemistry is more interesting than I had thought". The positive perception of this activity is even slightly higher for female students than for male students.

KEYWORDS: High School/Introductory Chemistry, Interdisciplinary/Multidisciplinary, Humor/Puzzles/Games, Periodicity/Periodic Table, Nomenclature/Units/Symbols

\section{INTRODUCTION}

It is a fact that many students regard chemistry as a subject that is hard to learn and sometimes also boring. Overcoming this setback demands the design of dynamic methodologies that are based on active learning and also are presented in an enjoyable way. Within this context, games and other fun activities have been revealed as excellent tools to make the learning of this scientific discipline more effective and less stressful. ${ }^{1-7}$

Understanding what matter is from a chemical point of view actually requires comprehending its essence, which basically is to interpret "what matter hides". Essentially, matter "hides" protons, electrons, and neutrons, thus giving rise to what we chemists actually describe/visualize as atoms. Transmitting and explaining this concept to students is almost always a very complicated task for the teachers since it requires a huge dose of mental abstraction by the students in order for them to understand it. In particular, this issue is a real challenge when it is being addressed for the first time with secondary school pupils. Usually, when these students begin the study of what matter is, they have already heard of atoms, elements, and composition previously, but most of them have not stopped to think seriously about these concepts. Moreover, it is noteworthy that even kids know, at a very early age, that scientists/ chemists call water " $\mathrm{H}_{2} \mathrm{O}$ ", although at heart they do not realize what they are saying and what that means. Trying to get a student to understand the concept of atoms as well as, very in particular, what a chemical formula is, what this really represents, and how important it is for chemists can be very stimulating for teachers, too. ${ }^{8}$

Writing chemical formulas and understanding what they mean requires being aware of what chemical elements are and what they represent in the context of chemistry. To do this, students need also to learn the names and symbols of the different elements, which are shown to them perfectly ordered in the periodic table. At this point, the study of our table as a

Received: January 2, 2021

Revised: March 30, 2021

Published: April 26, 2021 
whole and/or the chemical elements one by one is not usually well-appreciated by students because it means that they must cope with 118 chemical elements, the vast majority of them unknown to pupils. Furthermore, memorizing the chemical symbols associated with their names, which often seem arbitrary or counterintuitive, is found to be extremely boring and usually has a demotivating effect, bringing up feelings of anxiety to many students and quite often giving rise to disinterest. In an attempt to overcome these inconveniences, different strategies have been designed to engage students and help them learn and comprehend the periodic table, some of them successfully useful. ${ }^{8-15}$ Within this context, we have designed a further fun and participative activity that we have named FYPE (Find Your Personal Elements), which we herein describe. According to current regulations, in Spain the students face chemical formulation for the first time in grade 8 , which corresponds to the second year of Compulsory Secondary Education (ESO) in Spain; this stage is also the first contact of Spanish students with chemistry as an independent scientific subject. Therefore, this activity is mainly aimed at these students (13-14 years old).

\section{ACTIVITY}

FYPE is an adaptation of other activities based on the use of chemical symbols to write words and names, ${ }^{16-18}$ which we have properly revisited and adapted to ensure that students do carry out autonomous and incidental learning while having fun. Even more, the purpose of this activity is not only for students to understand chemical concepts but also for them to acquire soft skills and approach this subject without fear and/or insecurity. In terms of chemical concepts, the aim is for pupils to become familiar with the chemical elements by knowing their names and symbols and to understand what chemical composition is. They also learn that the elements they see arranged in the periodic table are present in the matter that surrounds us and of which we are all made. In terms of soft skills, students are expected to develop their creativity, learn how to manage time and make decisions, and improve their public speaking skills. In addition, this activity also allows students to improve their computer skills. With regard to the latter, it should be noted that the project is designed to make pupils begin to realize the transversality that exists in learning: they are able to learn computer science and graphic design even in chemistry class.

To achieve these goals, FYPE has been devised to contain three parts that are carried out consecutively over a month and a half:

1. Part 1: Writing the "personal chemical name".

2. Part 2: Flash presentation.

3. Part 3: Art exhibition open to the public.

\section{Part 1. Writing the "Personal Chemical Name"}

Students must write their names (or, alternatively, surnames or nicknames) with the help of the chemical symbols. This will lead them to a presumed "personal chemical composition" based on the elements that make up their names. They assume that the elements that build their corresponding names are those that particularly describe them in terms of their chemical composition and therefore conclude that "I am a compound of ... because my name is ...”. Moreover, students are also encouraged to write their "personal chemical formulas" by grouping the chemical elements that are repeated in their "personal chemical names". Conceptually, they comprehend that a chemical formula represents the minimum relationship of the elements contained in a particular type of matter. Since some names may be written "chemically" in more than one way, that is, using more than one combination of chemical elements, students are encouraged to check whether this is actually their case, which is notably appreciated.

In order to find their personal elements, students have to rummage through the chemical elements in the periodic table and put into practice the incidental learning. Without realizing it, they become familiar with the names of the different elements and catch onto the corresponding chemical symbols that are deeply related to their names. Singularly, the students often notice that letters "J" and "Q" are missing in the periodic table. Moreover, as the majority of Spanish names for women end with "A", the female students insistently look for chemical symbols containing this vowel; finding that only seven from the 118 symbols end with it ( $\mathrm{Na}, \mathrm{Ca}, \mathrm{Ba}, \mathrm{Ra}, \mathrm{Ta}$ and $\mathrm{La}$ ).

For this first part of the activity students, have three 1 hour sessions, and it takes place in the classroom, where they can make use of the computing facilities to prepare a personal poster that will be shown later in part 3. For this task the students are completely free, which allows them to develop their creativity; see an example in Figure 1.

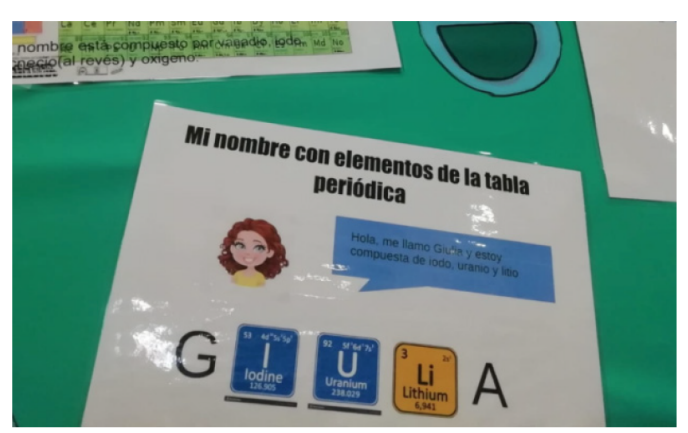

Figure 1. Example of a "personal composition" poster [translation: "My name with the elements of the periodic table: Hello, my name is Giulia and I'm composed of Iodine, Uranium and Lithium"].

\section{Part 2. Flash Presentation}

Usually, the first part of the activity awakes the curiosity of the students, who request more and more information about the elements that they have just "discovered" for themselves. The reasons for their names, how, when, where, and who discovered them, and/or the uses are the main interests demanded by the students. Therefore, as the second part of the activity, students have to choose one of the elements of "their personal formula", find information about it, and make a flash presentation (about $5 \mathrm{~min}$ ) to their classmates. Again, they have absolute freedom to select the element, keeping in mind that it has to be part of their chemical formula.

It should be noted that no element can be repeated during the flash presentations, so taking into account that there are about 20-25 students in each class, in the end the students will get to know in some detail at least that number of elements. With this part of the activity, the students take ownership of their learning as they freely decide the content and organization of their presentations. In any case, however, they are encouraged to include a brief explanation of the importance/influence of the chosen chemical element in our daily life. It is worth noting that quite often this activity awakens the interest of some students in learning more about 
some elements whose existence was unknown to them and they have just discovered in their amazing journey through the periodic table. This leads them to seek on their own (outside the activity) information about those other elements that have not been described in class but have drawn their attention as they have rummaged in the periodic table.

Presentations are given during the 2 weeks following the completion of part 1. Undoubtedly, the development of this part of the activity allows autonomous learning by the students. In addition, it also helps them to gain self-confidence as they are the ones who decide "what" (the element and contents), "how" (organization of the presentation), and "when" (there is no schedule; each student chooses a day).

\section{Part 3. Art Exhibition}

Finally, once part 2 is finished, an art exhibition with the posters that the students prepared in part 1 is carried out at the main hall of the high school (see Figure 2). There it stays for at

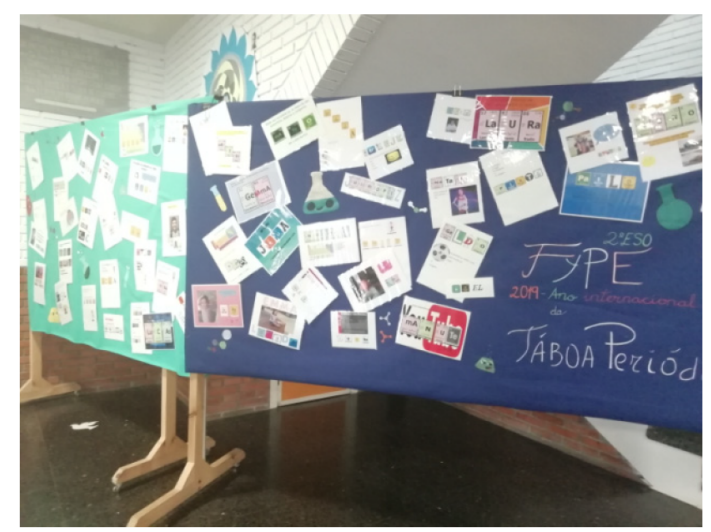

Figure 2. Open art exhibition at the main hall of the high school IES Punta Candieira (Cedeira, Spain) from the 2018-2019 academic year.

least 1 month in full view of all members of the school: students from other courses, teachers of different subjects, and administrative staff, who quite often stop to look at it and become interested in some of the symbols and chemical elements that appear there. Even sometimes, if they know particular students, they go to them to ask for more information. Moreover, parents and relatives are also invited to visit the exhibition, making this activity clearly go beyond the classroom. Although this part of the activity could be seen as minor or unimportant, that is not the case at all. At this point, students take great pride in being able to explain the concepts of chemistry to their loved ones and members of the school community, and this helps them gain self-confidence.

In this project, the teacher accompanies the students in all three phases, although with a much greater presence in the first two, in which the teacher helps the students by answering questions about chemistry as well as the use of computer programs and how to check the information found on the Internet. In the third part, the students are the absolute protagonists: their effort and work are valued, and they are clearly empowered.

\section{STUDENTS' PERCEPTIONS}

This activity was conducted with students in the eighth grade at the high school IES Punta Candieira in Cedeira, Spain, during the 2016-2017, 2017-2018, and 2018-2019 academic years (more details are provided in the Supporting Information). The drawbacks detected during the first edition (2016-2017), which were mainly related to the organization of the activity (schedule and computing facilities), were conveniently overcome, and during the second one (20172018) the learners revealed themselves to be very active. In particular, the students in the second edition found the first part of the activity-writing their names with the symbols of the chemical elements-so amazing that they realized they could use this strategy to write entire texts, and they actually did so. Because of the extra time consumed, the third part (art exhibition) had to be canceled. In any case, their longer activity of rummaging and traveling through the periodic table enabled them to recognize and identify practically all of the symbols of the chemical elements, which was very positively appreciated.

The students in the third edition (2018-2019) carried out the activity entirely, and their perceptions were assessed through an anonymous survey. All of the participants in the activity (60 in all, 32 males and 28 females) completed the survey, so the results are considered representative. The survey (see the Supporting Information) contained the following five statements:

Q1: The activity has been great fun.

Q2: This activity has helped me to learn about chemical elements that I did not know existed.

Q3: This activity has helped me to learn the names and symbols of the chemical elements.

Q4: This activity has aroused my curiosity: I'd like to learn more about the chemical elements.

Q5: Chemistry is more interesting than I thought.

A Likert-style response scale was used to evaluate the students' responses to these statements, with 5 being assigned to "Strongly Agree" and 1 to "Strongly Disagree", and the responses to each question were averaged (see Figure 3 and the Supporting Information).

Properly, FYPE was conceived not as a game but rather as a fun and entertaining activity to introduce chemistry to the students, which seems to have been achieved in light of their responses to Q1. Almost 77\% of the trainees chose "agree/ strongly agree", indicating that they consider this activity to be "great fun". Thirteen students were neutral, while only one student (out of 60) indicated having no fun at all. The average score on Q1 was 4.0 out of 5.0.

As mentioned above, with regard to the chemical contents, this activity has been devised to facilitate learning of the chemical elements, their symbols, and the concept of a chemical formula. The perception of the students about this was evaluated with the aid of Q2 and Q3: 82\% of students "agree/strongly agree" that this experience helped them to know the chemical elements, many of which were totally unknown to them, while ca. $65 \%$ acknowledged that this friendly activity made it easier for them to learn names and symbols of the chemical elements. It should be noted that the average score for Q2 ("This activity has helped me to learn about chemical elements that I didn't know existed") is particularly high (4.2 out of 5.0). Moreover, according to the answers to Q5, FYPE seems to have contributed to arousing the students' interest in the subject. Thus, around 60\% of the students clearly admitted that "Chemistry is more interesting than I thought” (Q5), and ca. 27\% were neutral. Finally, students were also asked to rate the activity as a whole, and the results are shown in Figure 4. With 1 being the minimum score 


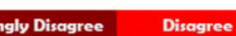

Neutral

Q1. This activity has been great fun

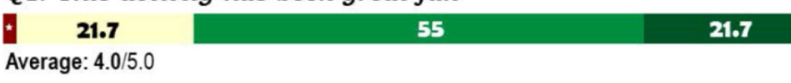

Q2. This activity has helped me to learn about Chemical Elements that I didn't know existed

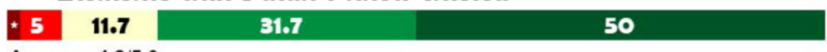

Average: $4.2 / 5.0$

Q3. This activity has helped me to learn the names and symbols of the Chemical Elements

11.723 .3

Average: $3.7 / 5.0$

Q4. This activity has aroused my curiosity: I'd like to learn more about the Chemical Elements

\begin{tabular}{|c|c|c|c|c|}
\hline 10 & 13.3 & 36.7 & 21.7 & 18.3 \\
\hline
\end{tabular}

Q5. Chemistry is more interesting than I thought

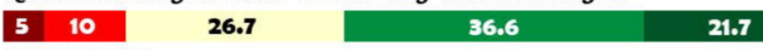

Average: $3.6 / 5.0$

$\%$ of Total Number of Records $(\boldsymbol{N}=60)\left[{ }^{*}(1.6)\right]$

Figure 3. Students' opinions $(N=60)$ : distribution of Likert categories and average scores.

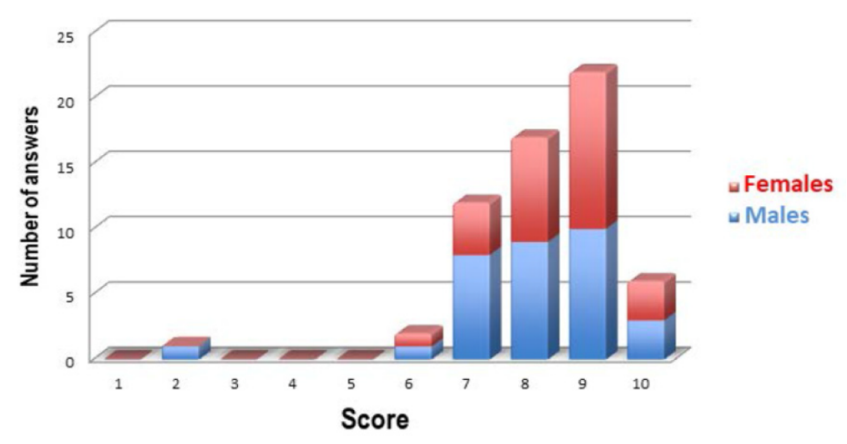

Figure 4. Overall assessment of the activity by students. Scores range from 1 (minimum) to 10 (maximum) $[N=60 ; 32$ males and 28 females].

and 10 the maximum, the majority of students (22 out of 60), both males and females, rated FYPE with a score of 9. The average was 8.20 , and therefore, it may be concluded that they liked this activity very much and felt it very positively. Personal comments by the students about the activity are included in the Supporting Information.

In general, there are no major differences in the students' appraisal of the activity depending on whether they are male or female, as can be seen from Figure 4 and also Table 1, which shows the responses to each question (expressed as percentages) organized by gender. In the context of the students' very positive opinion of this activity, females rate this activity a little better than males ( 8.43 vs 8.00 ; see Figure 4 and the Supporting Information) and also have a bit better perception ( $89 \%$ vs $75 \%$ ) regarding the help that FYPE provides them when it comes to knowing the chemical elements (Q2). However, slightly more males (44\% vs 36\%) stated that this activity awoke their curiosity and that they want to continue learning about chemical elements (Q4). Meanwhile, more females than males give the highest score "strongly agree” on Q4, and the responses to Q5 disaggregated by gender also show that, after having participated in this activity, $61 \%$ of female students think that chemistry is a "more interesting subject than I thought", a percentage even slightly higher than that of male students. At this point, however, it is also true that there are more females than males that had a negative response to Q5 (20\% of females disagreed or strongly disagreed vs $9 \%$ of males).

\section{FINAL CONSIDERATIONS AND FUTURE WORK}

In Find Your Personal Elements (FYPE), we have revisited the idea of writing words and names using chemical symbols, adapting it appropriately so that the students not only learn chemistry but also build skills. It is conceived not as a game but rather as a fun and entertaining activity to introduce chemistry to secondary students. The anxiety and stress usually felt by students when they have to face up to the study of the chemical elements and their symbols seems to be easily overcome with this activity, in which students look for their "personal elements" by rummaging through the periodic table. In particular, this activity gives pupils the opportunity to discover for themselves many elements that they have never heard of before and about which they ask for more information in many cases. In this way, unconsciously students become the protagonists of their own learning: they are not forced to study the chemical elements but do it by themselves according to their own curiosity.

Table 1. Comparison of Student Responses to the Survey Statements for the 2018-2019 Academic Year

\begin{tabular}{|c|c|c|c|c|c|c|c|c|c|c|c|}
\hline \multirow{3}{*}{\multicolumn{2}{|c|}{$\begin{array}{l}\text { Statements for Which Students Rated Their Level of } \\
\text { Agreement }{ }^{a}\end{array}$}} & \multicolumn{10}{|c|}{ Response Category Selected for Each Statement by Sex of Students (\%) } \\
\hline & & \multicolumn{2}{|c|}{ Strongly Agree } & \multicolumn{2}{|c|}{ Agree } & \multicolumn{2}{|c|}{ Neutral } & \multicolumn{2}{|c|}{ Disagree } & \multicolumn{2}{|c|}{$\begin{array}{l}\text { Strongly } \\
\text { Disagree }\end{array}$} \\
\hline & & $\mathrm{F}^{b}$ & $\mathbf{M}^{c}$ & $\mathrm{~F}^{b}$ & $\mathbf{M}^{c}$ & $\mathrm{~F}^{b}$ & $\mathbf{M}^{c}$ & $\mathrm{~F}^{b}$ & $\mathbf{M}^{c}$ & $\mathrm{~F}^{b}$ & $\mathbf{M}^{c}$ \\
\hline 1 & The activity has been great fun. & 28.57 & 15.63 & $50.00^{d}$ & $59.38^{e}$ & 21.43 & 21.87 & 0 & 0 & 0 & 3.12 \\
\hline 2 & $\begin{array}{l}\text { This activity has helped me to learn about chemical } \\
\text { elements that I did not know existed. }\end{array}$ & $46.43^{d}$ & $53.13^{e}$ & 42.86 & 21.87 & 7.14 & 15.63 & 3.57 & 6.25 & 0 & 3.12 \\
\hline 3 & $\begin{array}{l}\text { This activity has helped me to learn the names and } \\
\text { symbols of the chemical elements. }\end{array}$ & 14.29 & 21.87 & $50.00^{d}$ & $43.75^{e}$ & 21.43 & 25.00 & 14.29 & 9.38 & 0 & 0 \\
\hline 4 & $\begin{array}{l}\text { This activity has aroused my curiosity: I'd like to } \\
\text { learn more about the chemical elements. }\end{array}$ & 21.43 & 15.63 & 14.29 & $28.12^{e}$ & $50.00^{d}$ & 25.00 & 3.57 & 21.87 & 10.71 & 9.38 \\
\hline 5 & Chemistry is more interesting than I thought. & 17.86 & 25.00 & $42.86^{d}$ & 31.25 & 17.86 & $34.38^{e}$ & 17.86 & 3.12 & 3.57 & 6.25 \\
\hline
\end{tabular}

${ }^{a}$ Statements translated into English here by the authors. ${ }^{b}$ Female students, $N=28 .{ }^{c}$ Male students, $N=32 .{ }^{d}$ Most commonly selected response for this statement by female students. ${ }^{e}$ Most commonly selected response for this statement by male students. 
The students' perception of the activity was evaluated by means of a survey and is very positive, with a score of 8.20 (maximum 10). The results showed that $77 \%$ of the students considered it to be very fun, and moreover, $82 \%$ of them admitted that FYPE "had helped them to get to learn about elements that they did not know existed" and around 60\% considered that "Chemistry is more interesting than I thought". In terms of gender, we have noticed that there are no major differences in the students' appraisal of the activity although, females rate this activity a little better than males ( 8.43 vs 8.00 ) and also have a bit better perception ( $89 \%$ vs $75 \%$ ) regarding the help that FYPE provides them when it comes to knowing the chemical elements.

In light of the success of FYPE, currently we are involved in the development of a related activity named Find the Hidden Elements (FitHE), in which students have to find the chemical elements "hidden" in the names/surnames of different renowned scientists, therefore helping students also to learn some of history of chemistry through their main actors. In terms of its practical implementation, this new activity FitHE is being conceived as a competition among teams.

\section{ASSOCIATED CONTENT}

\section{SI Supporting Information}

The Supporting Information is available at https://pubs.acs.org/doi/10.1021/acs.jchemed.1c00002.

Implementation and complete survey results (PDF)

\section{AUTHOR INFORMATION}

\section{Corresponding Authors}

Teresa Rodríguez-Blas - Grupo de Innovación Educativa ReDU, Grupo METMED, Departamento de Química, Facultad de Ciencias and Centro de Investigaciones Científicas Avanzadas (CICA), Universidade da Coruña, 15071 A Coruña, Spain; (1) orcid.org/0000-0001-50781093; Email: teresa.rodriguez.blas@udc.es

Sofía Picos-Nebril - Departamento de Física y Química, Instituto de Enseñanza Secundaria (IES) Punta Candieira, 15357 Cedeira, A Coruña, Spain; Email: sofiapicos@ edu.xunta.gal

\section{Authors}

Andrés de Blas - Grupo de Innovación Educativa ReDU, Grupo METMED, Departamento de Química, Facultad de Ciencias and Centro de Investigaciones Científicas Avanzadas (CICA), Universidade da Coruña, 15071 A Coruña, Spain; (1) orcid.org/0000-0001-8548-9658

María-Jesús Latorre-López - Departamento de Física y Química, Instituto de Enseñanza Secundaria (IES) Punta Candieira, 15357 Cedeira, A Coruña, Spain

Complete contact information is available at: https://pubs.acs.org/10.1021/acs.jchemed.1c00002

Notes

The authors declare no competing financial interest.

\section{ACKNOWLEDGMENTS}

The authors thank the students of the High School IES Punta Candieira (Cedeira, Spain) who participated in this activity. We are also grateful to M. Prieto Díaz for his useful comments and to P. Pérez-Picos for his help in the design of some graphics.

\section{REFERENCES}

(1) Randel, J. M.; Morris, B. A.; Wetzel, C. D.; Whitehill, B. V. The Effectiveness of Games for Educational Purposes: A Review of Recent Research. Simul. Gaming 1992, 23, 261-276.

(2) Gredler, M. Educational Games and Simulations: A Technology in Search of a (Research) Paradigm. In The Handbook of Research for Educational Communications and Technology; The Association for Educational Communication and Technology: Bloomington, IN, 2001.

(3) Garris, R.; Ahlers, R.; Driskell, E. J. Games, Motivation, and Learning: A Research and Practice Model. Simulation \& Gaming 2002, 33, 441-467.

(4) Capps, K. Chemistry Taboo: An Active Learning Game for the General Chemistry Classroom. J. Chem. Educ. 2008, 85, 518.

(5) Antunes, M.; Pacheco, M. A. R.; Giovanela, M. Design and Implementation of an Educational Game for Teaching Chemistry in Higher Education. J. Chem. Educ. 2012, 89, 517-521.

(6) Franco-Mariscal, A. J.; Oliva-Martínez, J. M.; Almoraima Gil, M. L. Student's Perceptions about the Use of Educational Games as a Tool for Teaching the Periodic Table of Elements at the High School Level. J. Chem. Educ. 2015, 92, 278-285.

(7) Brassinne, K.; Reynders, M.; Coninx, K.; Guedens, W. Developing and Implementing GAPc, a Gamification Project in Chemistry, toward a Remote Active Student-Centered Chemistry Course Bridging the Gap between Precollege and Undergraduate Education. J. Chem. Educ. 2020, 97, 2147-2152.

(8) Yenikalaycı, N.; Çelikler, D.; Aksan, Z. Ion Hunters: Playing a Game To Practice Identifying Anions and Cations and Writing Their Names and Formulas. J. Chem. Educ. 2019, 96, 2532-2534.

(9) Granath, P. L.; Russell, J. V. Using Games to Teach Chemistry.

(1. The Old Prof Card Game). J. Chem. Educ. 1999, 76, 485-486.

(10) Kavak, N. ChemOkey: A Game to Reinforce Nomenclature. J. Chem. Educ. 2012, 89, 1047-1049.

(11) Bayir, E. Developing and Playing Chemistry Games to Learn about Elements, Compounds, and the Periodic Table: Elemental Periodica, Compundica, and Groupica. J. Chem. Educ. 2014, 91, 531535.

(12) Martí-Centelles, V.; Rubio-Magnieto, J. ChemMend: A Card Game to Introduce and Explore the Periodic Table while Engaging Student's Interest. J. Chem. Educ. 2014, 91, 868-871.

(13) Joag, S. D. An effective Method of Introducing the Periodic Table as a Crossword Puzzle at the High School Level. J. Chem. Educ. 2014, 91, 864-867.

(14) Hoffman, A.; Hennessy, M. The People Periodic Table: A Framework for Engaging Introductory Chemistry Students. J. Chem. Educ. 2018, 95, 281-285.

(15) Watson, G. S.; Green, D. W.; Watson, J. A. Introducing Students to the Periodic Table Using a Descriptive Approach of Superheroes, Meats, and Fruits and Nuts. J. Chem. Educ. 2021, 98, $669-672$.

(16) Eichstadt, K. A Large Lecture Hall Activity-Writing Your Name "in Chemistry". J. Chem. Educ. 1993, 70, 37.

(17) Palmer, J.; Brosnick, L. Designing Element T-shirts: Spelling with the Periodic Table. J. Chem. Educ. 2005, 82, 517.

(18) Woelk, K. How Heavy Are You? Find the Answer in the Periodic Table. J. Chem. Educ. 2015, 92, 1757-1758. 